\title{
Epidemiology of Breast Cancer in Ukraine, its Clinical and Genetic Special Features in Women from Kiev Region
}

K.P. Ganina, L.A. Naleskina, N.V. Boroday, Z.P. Fedorenko and R.E. Kavetsky

Institute of Experimental Pathology, Oncology and Radiobiology, National Academy of Sciences of Ukraine, Kiev, Ukraine

During the last decade most countries of the world have witnessed increased morbidity from breast cancer. When studying the basic oncologic morbidity of organs of the female reproductive system in Ukraine, including industrial regions, areas of strict radiation control were singled out following the Chernobyl nuclear accident. In Kiev and Kiev region we found that among female malignant neoplasms since 1977 the leading position belongs to breast cancer. A comparison of breast cancer morbidity prior to and after the Chernobyl accident revealed a trend to higher prevalence after the accident. The medical and geographic analysis of median standard values resulted in maps for distribution of breast cancer in Ukraine. The highest frequency of breast cancer is seen in industrial regions, Odessa region, Kiev and the Crimea. The genetic and mathematic analysis of patients with breast cancer from Kiev allowed us to determine a multi-factorial origin of this pathology. We have calculated the ratio of genetic and environmental components in the neoplastic process in patients with breast cancer $(56.58+3.68 \%$ and $43.42+3.86 \%)$. It was found that the family histories of patients with breast cancer often show accumulation of similar pathology and its association with other reproductive neoplasms and/or gastro-intestinal cancer. The densitometric analysis of DNA levels in epitheliocytes from oral cavity mucous membrane and special features of nuclear chromatin in peripheral blood lymphocytes helped to develop a diagnostic test. The findings obtained for Kiev region will be used for development of methodologic approaches for early diagnosis and prevention procedures in the group at high risk for contracting cancer of the reproductive system and gastro-intestinal tract. 


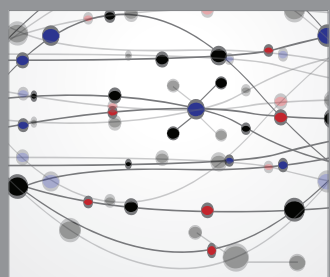

The Scientific World Journal
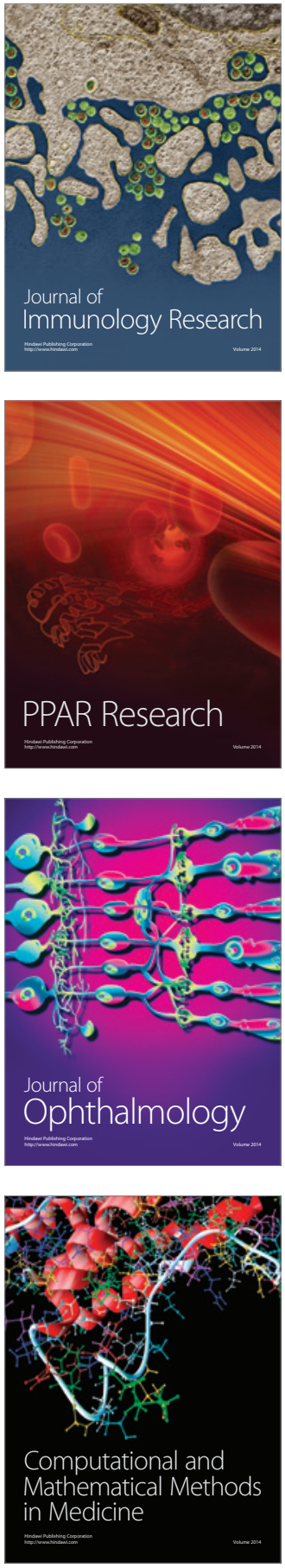

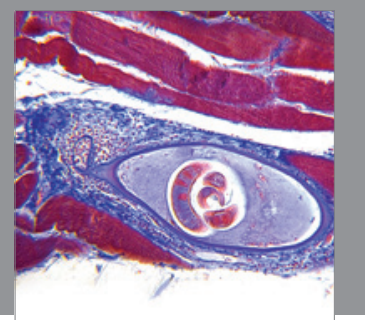

Gastroenterology

Research and Practice
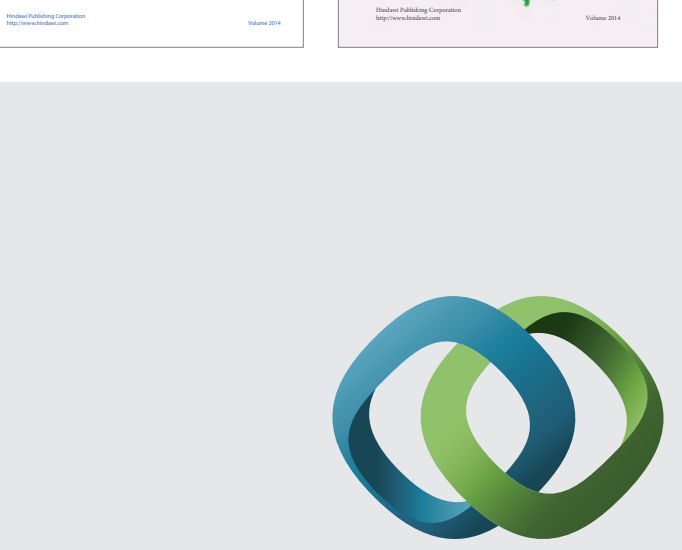

\section{Hindawi}

Submit your manuscripts at

http://www.hindawi.com
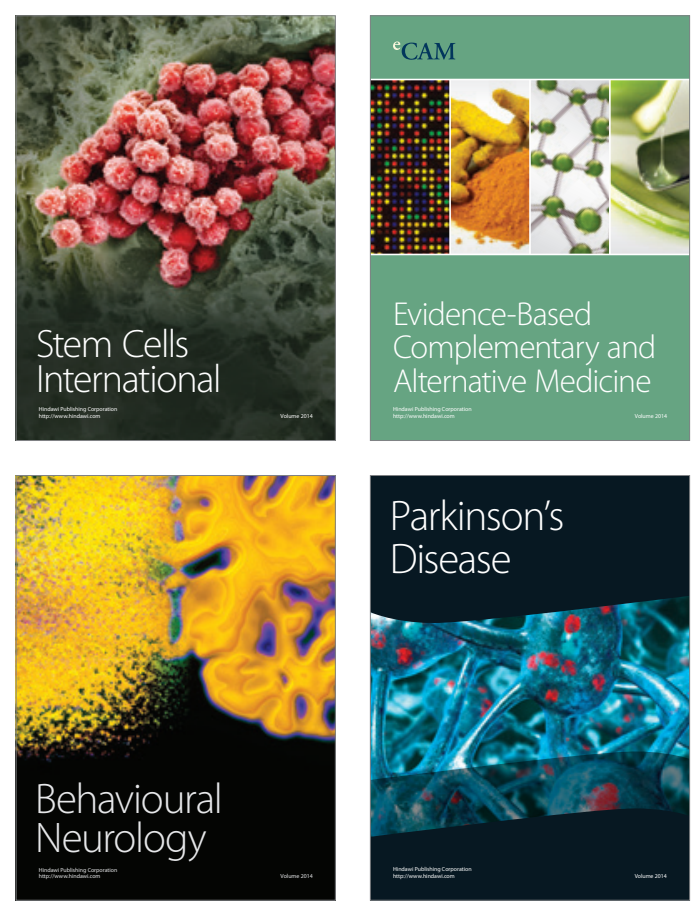

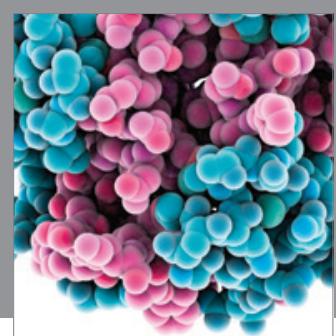

Journal of
Diabetes Research

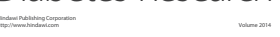

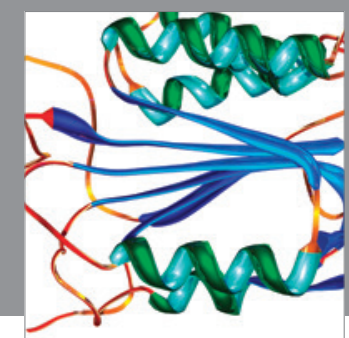

Disease Markers
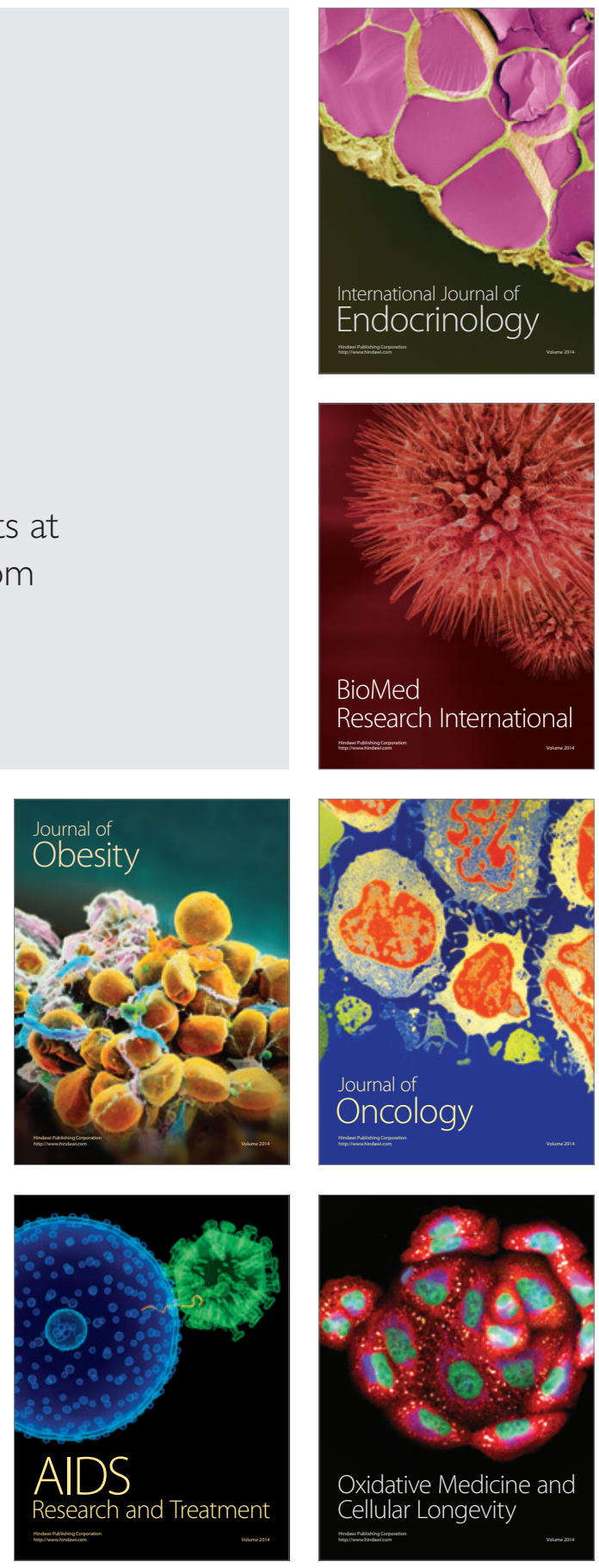